16. Боброва Н.Г. Аспекты применения технологии обучения в сотрудничестве при организации практической деятельности учащихся на уроках биологии // Научно-методический электронный журнал Концепт. 2014. № 7. С. 31-35.

17. Пономарева И.Н., Корнилова О.А., Чернова Н.М. Основы общей биологии: Учебник для учащихся 9 класса общеобразовательных учреждений / Под общ. ред. проф. И.Н. Пономаревой. М.: Вентана-Графф, 2013. $240 \mathrm{c}$.

18. Лисун Н.М. Формирование понятия «обмен веществ» в курсе общей биологии 10-11 класса: дис. ... канд. пед. наук (13.00.02 - теория и методика обучения и воспитания). Челябинск, 2011. $187 \mathrm{c}$.

19. Пономарева И.Н., Корнилова О.А., Лощилина Т.Е. Биология: 10 класс: базовый уровень учебник для учащихся общеобразовательных учреждений / Под общ. ред. проф. И.Н. Пономаревой. М.: Вентана-Графф, 2010. 224 c.

20. Пономарева И.Н., Корнилова О.А., Лощилина Т.Е., Ижевский П.В. Биология: 11 класс: базовый уровень: учебник для учащихся общеобразовательных учреждений / Под общ. ред. проф. И.Н. Пономаревой. М.: Вентана-Граф, 2013. 240 с.

\title{
THE CONTENT AND DEVELOPMENT OF BIOCHEMICAL CONCEPTS IN THE SCHOOL COURSE OF BIOLOGY
}

(C) 2016

\author{
I.V. Nalivayko, candidate of pedagogical sciences, associate professor \\ of the Chair of Biology, Ecology and Methods of Teaching \\ N.G. Bobrova, candidate of pedagogical sciences, associate professor \\ of the Chair of Biology, Ecology and Methods of Teaching \\ Samara State University of Social Sciences and Education, Samara (Russia)
}

\begin{abstract}
The article reveals the content of biochemical concepts constituting school biology course, shows their development during the study of all the units of the subject mentioned above: from the vegetable organism to the general laws of nature. Biology as a school subject is a system of biological concepts, developing in a logical sequence. The handling of the relevant concepts shows the degree of assimilation of biological knowledge. That is why the teacher's work on assimilation and development of biological concepts is so important.

The study of biochemical concepts is included in the school course of biology. They can be classified according to the nature of the content, along with morphological, anatomical concepts etc. Some biochemical concepts belong to the group of basic biological concepts, i.e. concepts about the biological regularities concerning with the whole wildlife. They are: «metabolism and interchange of energy», «nutrition», «breathing», «selection», «photosynthesis». A number of biochemical concepts such as «proteins», «carbohydrates», «vitamins», «enzymes» and some others are special, as they are studied within a specific section.

The article analyzes school curricula and textbooks on biology; it allows making a conclusion that biochemical concepts are formed and developed throughout the biology course from 6 to 11 grades. There is a succession in formation and development of these notions: at first they are special and are studied as processes characterizing the functioning of a plant; considering the processes occurring in animal organism, biochemical concepts become general. In the «General Biology» unit they become special again. Such regularity is substantiated by the logic of construction of biological material.

The formation of biochemical concepts is contributed to by all kinds of verbal, visual and practical methods of teaching biology, the role of the latter is particularly important. It requires the use of activity approach during the formation of biochemical concepts, because one of the conditions for their proper formation is the application of knowledge in practice. Skills acquired by students are the indicators of the effectiveness of education, together with the amount of subject knowledge.
\end{abstract}

Keywords: development of concepts, biological concepts, biochemical concepts, special concepts, research activity, an activity approach and practical training methods, biology, biochemistry.

УДК 378.147

\section{ПУТИ ОПТИМИЗАЦИИ ЮРИДИЧЕСКОГО ОБРАЗОВАНИЯ В РОССИИ}

(C) 2016

П.К. Рамазанова, кандидат филологических наук, доцент, заведующий кафедрой гуманитарных и социально-экономических дисциплин

3.А. Гаджиева, кандидат филологических наук,

доцент кафедры гуманитарных и социально-экономических дисциплин

Северо-Кавказский институт (филиал) Всероссийского государственного университета юстиичи в г. Махачкале, Махачкала (Россия)

\begin{abstract}
Аннотащия. В статье выявлены проблемы, которые возникают на этапе подготовки специалистов юридического профиля. Причем возросшее количество вузов не смогло оптимизировать, улучшить сложившуюся ситуацию. Авторы статьи анализируют причины ухудшения качества юридического образования. Предпринята попытка выявления пробелов в сфере юридического образования, т.к. только определение правильного диагноза болезни позволяет выбрать эффективное лечение. Для реформирования юридического образования необходимо привлекать представителей общественности, которые будут прослеживать процесс оптимизации вузов, налаживать контакты с факультетов с различными организациями. Необходимо предъявлять высокие требования к профессор-
\end{abstract}


ско-преподавательскому составу. Отправной точкой проблемы является падение качества среднего образования. Проводимые реформы зачастую негативно отражаются на образовательном процессе. Появившаяся возможность получить высшее образование платно приводит к дальнейшему обесцениванию образования, к беспрецедентным масштабам коррупции в образовательных учреждениях, к бурному росту количества разного рода низкосортных юридических вузов и факультетов, из года в год плодящих невежд с дипломами юриста-правоведа. Неоправданное приумножение филиалов, оказывающих так называемые образовательные услуги, не привело ни к повышению конкуренции между ними, ни к качественному улучшению юридического образования в стране. Серьезным минусом в подготовке будущих юристов является недостаточное внимание практическому аспекту обучения, в результате чего, обладая теоретическими знаниями, студенты, соприкасаясь с практической деятельностью, испытывают своеобразный комплекс неполноценности. Предложены пути оптимизации юридического образования.

Ключевые слова: Юрист; юридическое образование; образовательные учреждения; реформирование; учебный процесс; образовательный процесс; практический аспект обучения; оптимизация юридического образования

Требование модернизации высшего образования в Российской Федерации связано с социальными и экономическими преобразованиями общества, вызовом которого является необходимость изменения правовых актов организации и управления высшей школой, совершенствование содержания образования, технологии и методики преподавания, внедрение в вузовскую практику как инновационных, так и испытанных временем подходов. Как отмечает Н.А. Асваров: «Мы считаем необходимым проводить модернизацию образования таким образом, чтобы сблизить европейскую и российскую системы обучения, сохраняя при этом фундаментальные ценности и традиции в образовании, сложившиеся в России». [1]

Целью высшего профессионального образования является подготовка высококвалифицированных специалистов, причем квалификация предполагает не только высокий уровень фундаментальных научных знаний, но и умение применять их на практике, демонстрируя сформированную профкомпетентность. Особенно важно соблюдать эти требования в сфере подготовки юридических кадров, т.к. сформировать правовое государство без грамотных юристов невозможно, убедительным доказательством данного тезиса является высказывание академика О.Е. Кутафина: «Построить правовое государство без юристов - это все равно, что построить дом без строителей.» [2]

Профессия юриста относится к числу тех профессий, которые затрагивают все стороны жизнедеятельности человека. С древнейших времен юристы составляли некое элитное сообщество, олицетворяющее собой высокую духовность и нравственность, справедливость и законность. Но, к сожалению, в современном обществе происходит девальвация прежних духовных ценностей, что неизбежно приводит к деградации и утрате прежних высоких характеристик. Самоотверженная преданность профессии, порядочность, честность, требовательность, добросовестное выполнение своих профессиональных обязанностей - эти качества некоторыми юристами воспринимаются как анахронизм. Как отмечает Р.М. Акутаев: «Пожалуй, не будет преувеличением сказать, что современное состояние юридического образования... в стране в целом, мягко говоря, оставляет желать много лучшего». [3] Мы полагаем, что это во многом обусловлено серьезными недостатками в сфере подготовки специалистов юридического профиля. Бесспорно, что юридическое образование, впрочем, как и образование в целом, в настоящее время нуждается в серьезной модернизации. Речь идет не столько о правовой стороне вопроса, сколько о практической настройке механизма непрерывного образования и роли главных действующих лиц этого механизма - обучаемых, с одной стороны, и обучающих - с другой. В данной статье нами была предпринята попытка выявления пробелов в сфере юридического образования, так как только определение правильного диагноза болезни позволяет - выбрать эффективное лечение и наметить пути преодоления.

Первой составляющей проблемы является среднее обязательное образование, которое, образно говоря, своей мощной корневой системой призвано подпитывать древо высшей ступени образования, оно является фундаментом в деле налаживания образовательного и воспитательного процесса в высшей школе. В настоящий момент продолжается процесс реформирования школы, который заключается в радикальных изменениях, позволяющих учащимся адаптироваться к условиям быстро меняющегося мира, творчески реализовывать себя в жизни и в будущей профессии. [4] При необходимости ускоренного развития общества всегда возникает потребность в инновациях в системе образования. [5] Изначально так оно и было задумано, однако проведенная реформа, основным компонентом которой для абитуриентов стал отказ от проведения вступительных испытаний в виде классического экзамена и переход к оценке знаний в форме ЕГЭ, привела среднюю школу еще в более плачевное состояние, чем-то, в котором она находилась в дореформенный период. В некоторых регионах ЕГЭ стал мощным коррупциогенным фактором. Можно констатировать, что проведенная реформа не привела к ожидаемым результатам, так как получение фундаментальных знаний отступило на второй план, процесс школьного образования превратился в механическую работу по выбору верного варианта ответа на экзамене. Многие предметы, не обязательные для сдачи ЕГЭ, оставались вне поля зрения абитуриентов. Как положительный фактор можно отметить, что за последние годы попытки российского правительства, направленные на преодоление коррупциогенных явлений, привели к некоторым положительным изменениям. Но ситуация в Республике Дагестан свидетельствует о том, что коррупциогенность может быть устранена при наличии усилий со стороны заинтересованных структур. Тем не менее, накопленный за годы проведения реформы опыт убеждает нас в том, что ЕГЭ не должен и не может служить единственным универсальным критерием оценки знаний учащегося, дающим ему право определять выбор Вуза и факультета, особенно если речь идет о подготовке будущих юристов. Вот почему сегодня многие Вузы, учитывая набранные по ЕГЭ баллы, проводят дополнительный экзамен или собеседование. Однако это право распространяется далеко не на все вузы.

К сожалению, на этом этапе школьные реформы не были завершены, они приобретают перманентный ха- 
рактер, продолжая свое реформаторское шествие по стране и в наши дни.

Вот как их описывает директор Центра исследований постиндустриального общества, доктор экономических наук В. Иноземцев: «Реформы идут по всей стране: под лозунгами оптимизации ... сокращают часы истории, литературы и русского языка; массово вводятся платные (хотя формально и не обязательные) занятия». [6]

У этой проблемы есть и другая сторона. Абитуриент, не получивший глубоких знаний в школе и, соответственно, имеющий низкие баллы по ЕГЭ, имеет возможность поступить на внебюджетную форму обучения. На наш взгляд, это приводит к устранению состязательности абитуриентов, к дальнейшей девальвации образования, к беспрецедентным масштабам коррупции в образовательных учреждениях, к бурному росту разного рода низкосортных юридических Вузов и факультетов, из года в год плодящих невежд с дипломами юристов-правоведов. Студент не заинтересован в получении качественного образования, и он сам, и его родители свято верят, что платная форма защищает его от возможности исключения по неуспеваемости.

Можно обозначить еще один аспект. Речь идет об открытии по всей стране большого количества филиалов юридических вузов. Многие вузы, возникшие на волне коммерциализации образования, не соответствуют требованиям, предъявляемым государством к высшим учебным учреждениям. [7] Такое неоправданное приумножение филиалов, оказывающих так называемые образовательные услуги, не привело ни к повышению конкуренции между ними, ни к качественному улучшению юридического образования в стране. Попытаемся проанализировать причины и следствия этого. Дело в том, что многие созданные филиалы изначально не ставили перед собой цель обеспечить хотя бы средний уровень качества образования. Они создавались как доходные места для их руководителей, как объекты предпринимательской, а не образовательной деятельности. По сути, не с кем было конкурировать, так как их деятельность являлась существенным источником доходов для немалого количества должностных лиц, ответственных за выдачу соответствующих сертификатов и проведение лицензирования этих образовательных учреждений. Беспрецедентный количественный рост указанных учреждений рано или поздно должен был привести к острому дефициту квалифицированных педагогических кадров. [8] Как положительную следует рассматривать наблюдаемую тенденцию сокращения количества филиалов, не соответствующих предъявляемым требованиям. Примером могут служить прекратившие свою образовательную деятельность Московский институт мировой экономики и международных отношений, Московский социальногуманитарный институт в г. Таганроге. Институт (филиал) ФГБОУ ВПО «Московский юридический университет имени О.Е. Кутафина (МГЮА)» в г. Махачкале. В числе мероприятий по улучшению качества образования можно назвать ограничение на подготовку юристов в непрофильных вузах, а также, в целом, сокращение числа вузов, осуществляющих подготовку специалистов в области права, и непрофильных факультетов. [9]

Другая очень важная составляющая проблемы качественной подготовки юридических кадров - это сама система высшего профессионального образования. В
РФ на протяжении нескольких лет шли ожесточенные дискуссии о целесообразности организационных и методических инноваций в системе высшего образования. Итогом обсуждения стало введение новых государственных стандартов и переход на двухуровневую систему обучения. Но и для сторонников инноваций совершенно очевидно, что необходима преемственность, использование уже накопленного позитивного опыта. Очень важно, чтобы программа модернизации проводилась с учетом того, что в учебном процессе должно быть определенное выверенное соотношение традиционного и инновационного, «старого и нового». Для реализации этого необходимо постоянно стремиться к усовершенствованию методов и приемов обучения, этому во многом способствует обмен опытом. Заслуживает внимания положительный опыт Северо-Кавказского института (г.Махачкала) ВГУЮ. Активизация самостоятельной работы студентов достигается путем применения ряда новых образовательных технологий, к ним относятся такие методы активного обучения как деловые игры и метод конкретных ситуаций. На кафедре гражданского права и процесса СКИ ВГУЮ Минюста России данная методика активно применяется на занятиях по гражданскому праву, жилищному праву, семейному праву, земельному праву, экологическому праву. Рассмотрим практику использования деловой игры на занятиях по гражданско-правовому процессу. Студенты получают задание - самостоятельно составить фабулу любого гражданского дела. В группе проводится распределение ролей всех участников судебного процесса, от каждого участника требуется детальное знание функций выбранной роли. Преподаватель оказывает помощь, консультирует студентов, сам процесс записывается на видео. Проводится конкурс на лучший игровой процесс между группами. В СКИ ВГУЮ Минюста России создан фонд видеоматериалов по игровым процессам. Эти записи находятся в электронной библиотеке и могут быть использованы студентами. На кафедрах Вуза активно используется и метод конкретных ситуаций. Это метод активного проблемноситуативного анализа, основанный на обучении путем решения конкретных задач - ситуаций. Учебная ситуация конструируется преподавателем на основе реальной, актуальной с точки зрения информации. Использование метода формирует определенные профессиональные навыки в контексте научного и методического знания. Студент учится самостоятельно анализировать конкретную информацию, устанавливать причинноследственные связи, выделять ключевые проблемы. Преподаватель оценивает качество составленной задачи и правильность ее решения.

Мощным фактором, влияющим на модернизацию высшего образования, является информатизация, трудно переоценить ее роль в сфере правового образования. Системное использование компьютерной техники на занятиях способствует выработке у студента устойчивого интереса к обучению правовым дисциплинам, обусловленного внедрением в учебный процесс информационных технологий. Информатизация способствует расширению сферы самостоятельности в плане познания и решения проблемных вопросов, обеспечению доступности научного и практического фактологического материала. Средствами реализации информатизации правового образования являются прикладные программы, программы пакета Microsoft Office и 
электронные образовательные ресурсы. К правовым информационным возможностям интернета можно отнести организацию в режиме онлайн - конференции, форума, поиск информации правового содержания, учебно-исследовательскую работу с порталами и сайтами Вуза, где обучается студент. Например, в СКИ ВГУЮ Минюста России на практических занятиях по земельному и экологическому праву студенты получают задание рассмотреть конкретное дело, что требует проработки нескольких нормативно-правовых актов, или сделать обзор по изменениям, внесенным в законодательство за последнее время. От студентов требуется умение использования компьютерных справочно-правовых систем «Консультант плюс», «Кодекс», «Право», «Гарант».

К традиционным образовательным технологиям относится лекция и работа с источниками, но и здесь при наличии творческого подхода возможно новаторство. В СКИ ВГУЮ Минюста России на занятиях по земельному праву применяется новая методика: студенты самостоятельно по плану лекции, предварительно предложенному им преподавателем, прорабатывают материал по изучаемой теме. Во время занятий лектор в тезисном порядке рассматривает ключевые вопросы темы и затем приглашает студентов принять участие в обсуждении. Лекция проходит в форме диалога. Определенная часть обсуждаемого материала отображается на интерактивной доске. В результате совместной работы преподавателя и студентов формируются выводы и заключение. Инновационным является то, что студенты получают знания не в готовом виде, а в результате самостоятельной работы по получению информации и ее осмыслению. Нельзя не согласиться с мнением П.А. Раджабовой, которая отмечает: «Когда мы говорим об инновациях, то, по сути, речь идет о том, чтобы вооружить классические методы новыми техническими средствами - широко использовать электронные информационные системы, интерактивные доски и т.д. Новое требование к лекционным занятиям - это обязательное насыщение материалов лекций практическими примерами». [10]

Серьезным минусом в подготовке будущих юристов является недостаточное внимание практическому аспекту обучения, в результате чего, обладая теоретическими знаниями, студенты, соприкасаясь с практической деятельностью, испытывают своеобразный комплекс неполноценности. Заслуживает внимания положительный опыт Северо-Кавказского института ВГУЮ. Стремясь к реализации принципа единства теории и практики руководство нашего института активно привлекает к участию в образовательном процессе высокопрофессиональных специалистов-практиков, работающих в различных структурах ПО. Совершенствованию практической подготовки способствует и прохождение студентами производственной практики, которая в нашем вузе обязательна с 1 курса. Она позволяет молодым специалистам преодолеть те трудности, с которыми он неизбежно столкнется в будущем в своей профессии. Наряду с теоретическими знаниями, он должен обладать навыками составления юридически значимых документов. Но какими навыками может овладеть студент, который находится на заочной и дистанционной форме обучения? На наш взгляд они не гарантируют качественного образования. Подобной точки зрения придерживаются еще несколько ведущих ВУЗов страны. Так, в МГУ заочное отделение есть только на одном факультете, а в МГИМО такой формы обучения не существует вовсе. «Образование - это всетаки не рынок, - говорит Виктор Садовничий. - А потому критерий качества здесь гораздо важнее законов спроса и предложения». Ректор МГУ уверен, что каким бы высоким ни был спрос на заочное отделение, подготовить специалиста по фундаментальным направлениям можно только очно.

Необходимо отметить, что, несмотря на необходимость применения инновационных технологий в процессе обучения, роль преподавателя в подготовке специалиста не только не уменьшается, а, напротив, становится еще более значимой. В новых условиях педагогическая составляющая профессиональной компетентности преподавателя юридических дисциплин приобретает большее значение. Это нашло отражение и в организации учебного процесса в стенах СКИ ВГУЮ. Администрация вуза стала требовательнее относится к остепененности педагогического состава, с целью увеличить процентное соотношение педагогов с учеными степенями. Это послужило своеобразным толчком к активизации научно-исследовательской деятельности профессорско-преподавательского состава института, к росту требований к качеству результатов исследований. Конкурентные, творческо-соревновательные начала должны быть основополагающими в научнопедагогической деятельности кафедр. При этом к образовательной деятельности должны быть допущены лучшие из лучших представителей кафедр, имеющие опыт как научно-педагогической, так и практической деятельности вне стен вуза. Оценка деятельности педагога должна основываться не столько на заслугах прежних лет, сколько за вклад в текущую научнопедагогическую деятельность коллектива, за внедрение в ученый процесс новых современных методов обучения, в том числе основанных на новейших информационных технологиях.

Подводя итог, мы хотим наметить основные направления оптимизации положения, сложившегося в системе подготовки юридических кадров. Это предоставление вузам возможности проведения дополнительного собеседования с учетом баллов ЕГЭ, усовершенствование системы контроля подготовки студентов, находящихся на очной и дистанционной форме обучения. Для устранения существующего разрыва теории и практики в образовательном процессе можно рекомендовать активнее привлекать студентов к участию в работе системы бесплатной юридической помощи. Юридические клиники, студенческие консультации, юридические бюро дают возможность будущим специалистам усовершенствовать знания в правовом консультировании как в устной, так и в письменной форме.

Из всего сказанного, очевидно, что, только устранив обозначенные пробелы в подготовке юридических кадров, мы сумеем добиться оптимизации процесса обучения будущих правоведов. Реформирование юридического образования немыслимо без широкого вовлечения в этот процесс представителей общественности, организаций и средств массовой информации. Именно они, в качестве независимых арбитров, должны постоянно осуществлять мониторинг вопросов, касающихся оптимизации обучения юридических вызов, функционирования функциональных лифтов в государственных организациях юридического профиля. Оздоровление юридического образования в стране - часть, и, как мы полагаем, весьма важная часть, общего дела оздоров- 
ления общества, формирующего правовое государство, для чего, прежде всего, нужны юридически грамотные и квалифицированные специалисты.

\section{СПИСОК ЛИТЕРАТУРЫ:}

1. Асваров Н.А. Некоторые результаты общественного мнения в России и Дагестане о введении ЕГЭ и Болонской системы // Перспективы и пути развития образования в России и в мире: Материалы I Международной научно-практической конференции. Махачкала, 2012. С. 23.

2. Синцов Г.В. К вопросу об этическом воспитании юристов в современной России // Российская юстиция. 2012. № 11. С. 37.

3. Акутаев Р.М. Некоторые аспекты совершенствования юридического образования // Перспективы и пути развития образования в России и в мире: Материалы II Международной научно-практической конференции. Махачкала, 2013. С. 12.

4. Асваров Н.А. Профессионализм учителя - основа качества образования // Перспективы и пути развития образования в России и в мире: Материалы II Международной научно-практической конференции. Махачкала, 2013. С. 36.

5. Щербаков А.Л. Психологические основы формирования личности учителя. М., 1967. С. 21.
6. Магомедов М.А. Некоторые актуальные проблемы качества юридического образования в России // Перспективы и пути развития образования в России и в мире: Материалы II Международной научно-практической конференции. Махачкала, 2013. С. 60.

7. Магомедов А.М. Основные проблемы высшего образования // Перспективы и пути развития образования в России и в мире: Материалы II Международной научно-практической конференции. Махачкала, 2013. C. 57.

8. Акутаев Р.М. К вопросу о совершенствовании юридического образования // Проблемы развития образования на современном этапе: Материалы II Международной научно-практической конференции. Махачкала, 2014. С. 9.

9. Магомедов М.А. Некоторые актуальные проблемы качества юридического образования в России // Перспективы и пути развития образования в России и в мире: Материалы II Международной научно-практической конференции. Махачкала, 2013. С. 60.

10. Раджабова П.А. Сочетание традиционных и инновационных методов обучение на юридическом факультете // Юридическое образование и наука. 2014. № 1. C. 20 .

\section{THE WAYS OF OPTIMIZATION OF LEGAL EDUCATION IN RUSSIA}

P.K. Ramazanova, candidate of philological sciences, associate professor, head of the Chair of Humanitarian and Socio-Economic Disciplines

Z.A. Gadjiyeva, candidate of philological sciences, associate professor of the Chair of Humanitarian and Socio-Economic Disciplines North Caucasus Institute (Branch) of Russian State University of Justice, Makhachkala (Russia)

Abstract. The article reveals the problems that arise during the preparation of law specialists. Moreover, the increasing number of universities are not able to resolve the situation. The authors analyze the reasons of deterioration of the quality of law education. An attempt to identify gaps in the field of law education has been made, as only proper diagnosis of the disease allows you to select effective treatment. In order to reform law education, it is necessary to involve members of the community who will watch the process of the university optimization, establish contacts between the faculties and various organizations. It is necessary to be more exacting to the teaching staff. The core problem is a drop in the quality of secondary education. The reforms have had a negative impact on the educational process. The opportunity to graduate for a fee leads to a further devaluation of education, to the unprecedented scale of corruption in educational institutions, to the rapid increase in the number of low-grade law schools and faculties producing ignoramuses with lawyer diplomas from year to year. Unjustified multiplication of the university branches has not led to either an increase in competition between them or to improvement of the quality of law education in our country. A serious drawback in preparation of future lawyers is a lack of attention to the practical aspect of the training, as a result, having textbook knowledge only, the students getting down to real work experience a kind of inferiority complex. Ways of optimization of legal education aresuggested.

Keywords: lawyer, law education, educational institutions, reforming, educational process, practical aspect of learning, optimization of law education, institute, branch.

УДК 371.21(09) С19

\section{АРТИЛЛЕРИЙСКИЙ И ИНЖЕНЕРНЫЙ ШЛЯХЕТСКИЙ КАДЕТСКИЙ КОРПУС КАК ЗНАЧИМАЯ ЧАСТЬ СИСТЕМЫ ПОДГОТОВКИ ВОЕННЫХ КАДРОВ В РОССИИ}

(C) 2016

М.П. Стародубцев, кандидат педагогических наук, доцент, профессор кафедры философских и социально-экономических наук Санкт-Петербургский военный институт внутренних войск МВД России, Санкт-Петербург (Россия)

Аннотация. В условиях модернизации Вооруженных Сил Российской Федерации, переход к новому облику офицера, перед военной педагогикой Российской Федерации сегодня стоят сложные и важные задачи, это научное обоснования процессов становления и подготовки офицерских кадров, способных решать задачи по безопасности государства, и реформирование такой системы военного образования, которая отвечала бы приоритетным задачам Вооруженных Сил России. Данные факты обуславливают необходимость обратиться к опыту истории Самарский научный вестник. 2016. № 1 (14) 